\title{
THE NEOLITHIC SITE OF SERRA CICORA: RESULTS OF THE AMS RADIOCARBON DATING
}

\author{
G Quarta $^{1,2} \bullet \mathrm{M}^{\prime}$ Elia $^{1} \bullet$ E Ingravallo $^{3} \bullet$ I Tiberi $^{3} \bullet \mathrm{L} \mathrm{Calcagnile}^{1}$
}

\begin{abstract}
Bone and charcoal samples from the Neolithic site of Serra Cicora in the Salento Peninsula (southern Italy) have been dated by accelerator mass spectrometry (AMS). Measurements appear to support other archaeological evidence and have shown that 2 distinct phases of human occupation of the site can be identified: the first occupation in the Early Neolithic and a second occupation in the Middle-Late Neolithic. The results provide new information and are a fundamental contribution to the definition of the absolute chronology of the Middle-Late Neolithic in this part of Europe.
\end{abstract}

\section{INTRODUCTION}

The Neolithic site of Serra Cicora is about $1 \mathrm{~km}$ from the Ionian coast of the Salento Peninsula in southern Italy $\left(40^{\circ} 10^{\prime} \mathrm{N}, 18^{\circ} 01^{\prime} \mathrm{E}\right)$. The site lies about $50 \mathrm{~m}$ from the shoreline and approximately $50 \mathrm{~m}$ above sea level on the flat top of a small hill. Serra Cicora has been excavated since 1998 by archaeologists of the Department of Cultural Heritage of the University of Lecce (Lecce, Italy), who have found evidence of human presence since ancient times, including burials, pottery, post holes, and artifacts. An archaeological analysis of the site structure and a stylistic analysis of the pottery suggest that human occupation took place in 2 distinct phases in Serra Cicora: the first phase in the Early Neolithic and the second phase in the Middle-Late Neolithic. Pottery from the first phase at the site, ascribed to the cultural aspect of "Impressed Pottery," was associated with several post holes excavated in the basement rocks, which suggested the presence of huts. The second phase at the site, ascribed to the cultural aspects of "Serra d'Alto" and "Diana," is notable for its many burials of a characteristic circular shape (Figure 1). This suggests that in this period the site was used mainly as a necropolis (Cipolloni Sampò 1998).

\section{METHODS: SAMPLE SELECTION AND AMS DATING}

This study is one of the first systematic investigations regarding archaeological applications carried out in Lecce using the new accelerator mass spectrometry (AMS) system. In this study, we investigated 2 apparently distinct phases of human occupation at Serra Cicora. The material suitable for our purpose from excavations on the first Early phase was charcoal found in one of the post holes, assumed to be combusted wood of the posts. For the second phase, 6 human bone samples were selected from 6 different burials. The samples listed in Table 1 were dated at the AMS Radiocarbon Dating Facility of the University of Lecce (laboratory code LTL) (Calcagnile et al. $2004 \mathrm{a}, \mathrm{b}$ ) and, for comparison, duplicate samples were sent to the Leibniz Labor für Altersbestimmung und Isotopenforschung of Christian Albrechts University (Kiel, Germany; laboratory code KIA).

The selected bone samples were generally well preserved and did not show any evident source of contamination (i.e. presence of roots, restoration substances, carbonate-rich layers).

Collagen survival in the bones was similar for all the samples, and for one of them, T3 IN. A (SECT.V), the percentage of original collagen remaining in the bone was determined to be $2.8 \%$, a low yield when compared with a content of about $22 \mathrm{wt} \%$ for a fresh bone (van Klinken 1999).

\footnotetext{
${ }^{1}$ Dipartimento di Ingegneria dell'Innovazione, Università di Lecce, via Monteroni, Lecce, Italy.

${ }^{2}$ Corresponding author. Email: glquarta@mailing.unile.it.

${ }^{3}$ Dipartimento di Beni Culturali, Università di Lecce, via D. Birago, Lecce, Italy.
} 


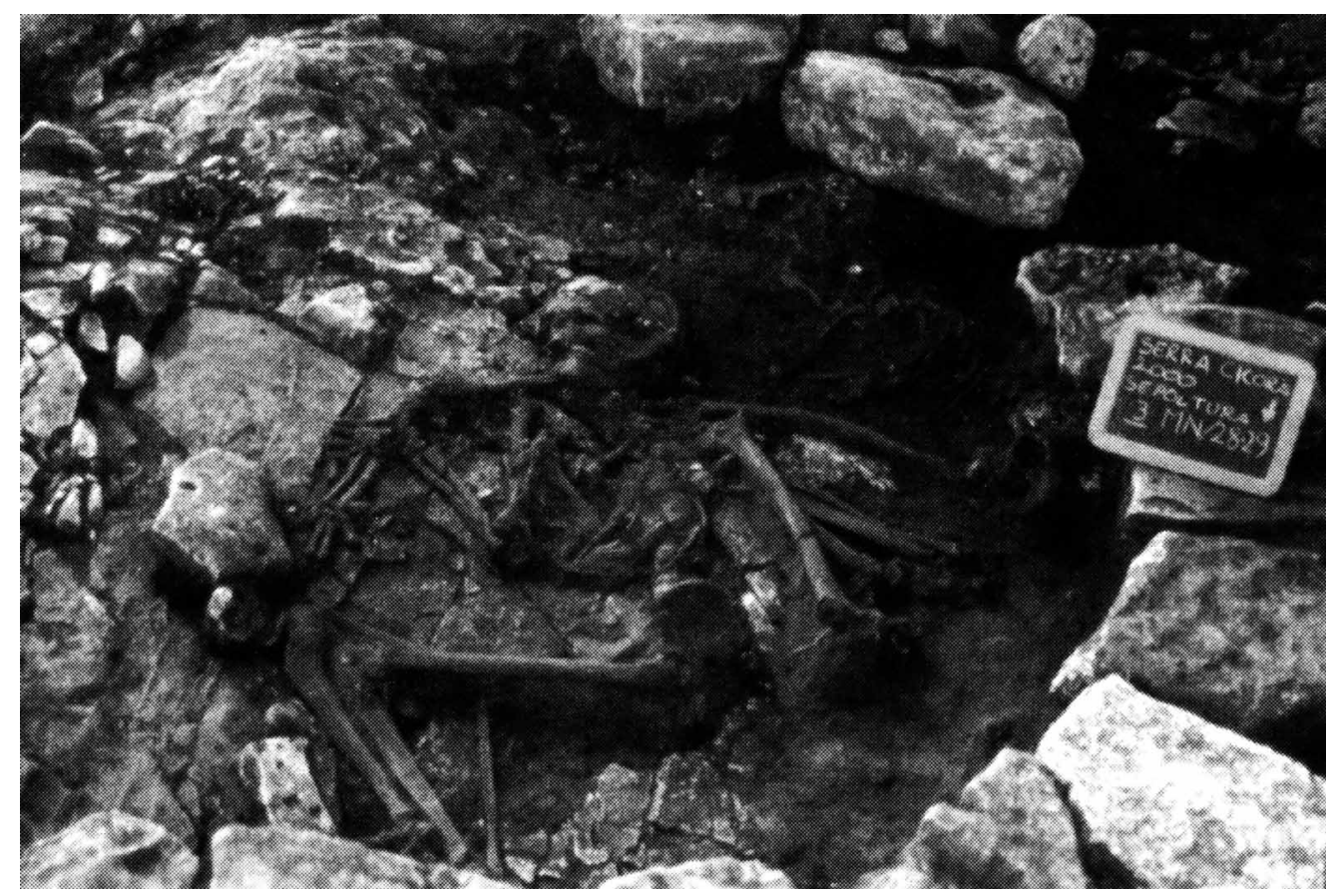

Figure 1 One of the dated individuals (T3 IND.A-Sect V) in one of the characteristic circular burials of Serra Cicora

For the preparation of the bone samples, a modified method by Longin (1970) was used to extract the collagen fraction (D'Elia et al. 2004; Gillespie et al. 1984). In particular, an additional alkali solution $(0.2 \mathrm{M} \mathrm{NaOH}$ for $30 \mathrm{~min})$ was added before the collagen solubilization in hot water $\left(85^{\circ} \mathrm{C}\right)$, and acidified at $\mathrm{pH}=3$ with $\mathrm{HCl}$ for about $8 \mathrm{hr}$.

All the charcoal samples were mixed with significant quantities of inorganic material (most likely clay used to fix the posts in the holes) and were treated by the cunventional acid-alkali-acid (AAA) method (D'Elia et al. 2002). The samples of chemically treated charcoal and purified bone protein were combusted in evacuated sealed quartz tubes in a muffle oven at $900{ }^{\circ} \mathrm{C}$ for $8 \mathrm{hr}$. The resulting $\mathrm{CO}_{2}$ was cryogenically purified (D'Elia et al. 2002) and then converted to graphite by using $\mathrm{H}_{2}$ as the reductant and iron powder as the catalyst (D'Elia et al. 2004; Vogel et al. 1984).

All the bone samples yielded enough graphite to allow precise ${ }^{14} \mathrm{C}$ measurements in the accelerator, while only two of the charcoal samples yielded — during the sample processing - enough graphite to allow reliable measurements with the accelerator.

Graphite targets were then submitted for ${ }^{14} \mathrm{C}$ dating. The measured values were normalized by using NIST Oxalic Acid II standards and IAEA C6 Sucrose as quality and accuracy controls. The measured isotopic ratios were corrected for accelerator and sample preparation background and for isotopic fractionation by using the ${ }^{13} \mathrm{C} /{ }^{12} \mathrm{C}$ ratio measured by the accelerator. The background correction was done by subtracting the accelerator and sample processing-induced backgrounds (estimated by measuring ${ }^{14} \mathrm{C}$-free blank materials) from the samples' measured isotopic ratios, and by taking into account the sample mass dependency (Morgenroth et al. 2000; Rom et al. 1998).

For the IAEA C6 Sucrose, a ${ }^{14} \mathrm{C}$ concentration of $1.5044 \pm 0.55 \mathrm{pMC}$ was measured, showing good agreement $(0.1 \%$ relative difference $)$ with the IAEA consensus value $(1.5061 \mathrm{pMC})$. 


\section{RESULTS AND DISCUSSION}

Table 1 reports the measured ${ }^{14} \mathrm{C}$ ages and ${ }^{13} \mathrm{C}$ values for the samples. Since the ${ }^{13} \mathrm{C}$ term was measured with the accelerator, its value reflects not only the naturally occurring mass fractionaction, but also the mass fractionaction induced by sample processing and by the AMS measurement itself (Quarta et al. 2005).

Table 1 Summary of the dated samples.

\begin{tabular}{lllll}
\hline Sample ID & Sample material & Lab nr & ${ }^{14}$ C age (BP) & ${ }^{13} \mathrm{C}(\%)$ \\
\hline SC99143 & Charcoal & KIA10827 & $6679 \pm 54$ & $-26.32 \pm 0.06$ \\
SC02 QL1 t1 N.4 (SECT.VI) & Charcoal & LTL026A & $6762 \pm 55$ & $-18.80 \pm 0.20$ \\
T3 IN. A (SECT.V) & Human bone (Burial T3) & KIA13292 & $5685 \pm 43$ & $-18.43 \pm 0.16$ \\
T3 IN. A (SECT.V) & Human bone (Burial T3) & LTL010A & $5690 \pm 44$ & $-18.36 \pm 0.35$ \\
T4 (Sect. VI) & Human bone (Burial T4) & KIA13293 & $5648 \pm 34$ & $-20.14 \pm 0.07$ \\
Q N-O 4 T9 & Human bone (Burial T9) & LTL033A & $5591 \pm 44$ & $-17.08 \pm 0.67$ \\
QEG25-26 T6 & Human bone (Burial T6) & LTL029A & $5531 \pm 52$ & $-19.01 \pm 0.13$ \\
SC03 T10 IN.A (SECT. VI) & Human bone (Burial T10) & LTL145A & $5686 \pm 37$ & $-20.21 \pm 0.15$ \\
SC03 T11 (SECT. V) & Human bone (Burial T11) & LTL147A & $5575 \pm 55$ & $-21.90 \pm 0.20$ \\
\hline
\end{tabular}

Although in order to really check if the extracted collagen was free of contamination and if any kind of reservoir effect (i.e. related to paleodietary) was present, more information about the atomic $\mathrm{C} / \mathrm{N}$ ratio or the ${ }^{15} \mathrm{~N}$ should be collected. The ${ }^{13} \mathrm{C}$ values measured for collagen and the consistency of all the data are a significant indication of the effectiveness of the contamination removal, and thus of the reliability of the obtained results.

The sample T3 In.A (Sect. V) was dated both in Lecce and in Kiel for intercomparison. The ${ }^{14} \mathrm{C}$ ages measured in the 2 labs are in good agreement, with a relative difference below $0.1 \%$. The ${ }^{14} \mathrm{C}$ ages have been corrected in calendar dates by using the software OxCal v 3.5, based on the last atmospheric data set (Stuiver et al. 1998); the results are given in Figure 2. The measurements clearly confirm that the human occupation of Serra Cicora took place in 2 distinct moments: the first occurring near the onset of the Early Neolithic (5670-5480 cal BC) and a second in the Middle-Late Neolithic (4600-4300 cal BC).

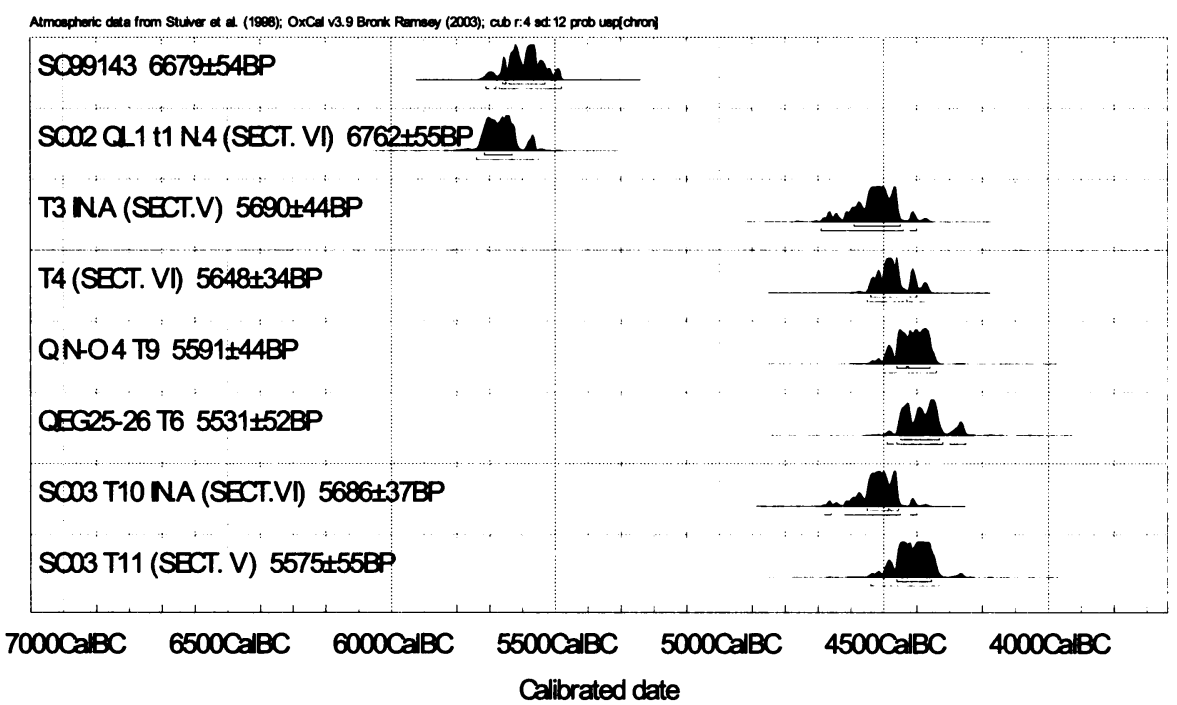

Figure 2 Results of the calibration. The charcoal samples (SC99143 and SC02 QL1 t1 N.4) belong to the first phase (Early Neolithic), while all the other samples are attributed to the second phase (Middle-Late Neolithic). 


\section{CONCLUSIONS}

Results of the ${ }^{14} \mathrm{C}$ analysis can be interpreted on 2 levels. On a local, regional scale, the measurements provide a fundamental contribution to the identification and absolute dating of the 2 moments of human occupation of Serra Cicora, with the first being one of the oldest Neolithic sites in southern Italy. On a larger geographical scale, however, the results are even more important, since they present one of the first absolute dates for the 2 cultural aspects Serra d'Alto and Diana, which were diffused in the whole Italian peninsula in the Middle-Late Neolithic. Such results, although still preliminary, suggest that an intensive, methodical study should be carried out in order to reconstruct an absolute time frame for the whole Italian Neolithic. On this basic idea and in collaboration with several Italian universities, museums, and the Conservation Institution of the Italian Ministry for the Cultural Heritage, several materials (charcoal, animal and human bones, marine shells) attributed to different local Neolithic cultures have been selected and are now being dated by AMS in Lecce. The results of this project, which is only in its preliminary stage, has already led to the dating of more than 100 samples from all around Italy. More results will be reported in future publications.

\section{ACKNOWLEDGMENTS}

We wish to thank the Paleoethnology group of the Department of Cultural Heritage of the University of Lecce for the many helpful discussions.

\section{REFERENCES}

Calcagnile L, Quarta G, D'Elia M, Rizzo A, Gottdang A, Klein M, Mous DJW. 2004a. A new accelerator mass spectrometry facility in Lecce, Italy. In: Proceedings of the Ninth International Conference on Accelerator Mass Spectrometry. Nuclear Instruments and Methods in Physics Research B 223-224:16-20.

Calcagnile L, Quarta G, D'Elia M, Gottdang A, Klein M, Mous DJW. 2004b. Radiocarbon precision tests at the Lecce AMS facility using a sequential injection system. Nuclear Instruments and Methods in Physics Research B 215:561-4.

Cipolloni Sampò M. 1998. L'Italie du sud. In: Atlas du Neolithique Europeen, L'Europe Occidentale, Volume $2 A$. Liegi: Etudes et recherches archeologiques de l'universite de liege. p 9-54.

D'Elia M, Quarta G, Sanapo C, Laudisa M, Rizzo A, Calcagnile L. 2002. Dating a medieval painting prepared on the new AMS sample preparation lines in Lecce. Paper presented at the International Conference ${ }^{14} \mathrm{C}$ and Archaeology, Oxford, 2002.

D'Elia M, Calcagnile L, Quarta G, Sanapo C, Laudisa M, Toma U, Rizzo A. 2004. Sample preparation and blank values at the AMS radiocarbon facility of the University of Lecce. In: Proceedings of the Ninth International Conference on Accelerator Mass Spectrometry. Nuclear Instruments and Methods in Physics Research B 223-224:278-83.

Gillespie R, Hedges REM, Wand JO. 1984. Radiocarbon dating of bone by accelerator mass spectrometry. Journal of Archaeological Science 11:165-70.

Longin R. 1970. New method of collagen extraction for radiocarbon dating. Nature 230:241.

Morgenroth G Kerscher H, Kretschmer W, Klein M, Reichel M, Tully T, Wrzosok I. 2000. Improved sample preparation techniques at the Erlangen AMS facility. Nuclear Instruments and Methods in Physics Research B 172:416-23.

Quarta G, D'Elia M, Valzano D, Calcagnile L. 2005. New bomb pulse radiocarbon records from annual tree rings in the Northern Hemisphere temperate region. Radiocarbon 47(1):27-30.

Rom W, Golser R, Kutschera W, Priller A, Steier P, Wild E. 1998. Systematic investigations of ${ }^{14} \mathrm{C}$ measurements at the Vienna Environmental Research Accelerator. Radiocarbon 40(1):255-63.

Stuiver M, Reimer PJ, Bard E, Beck JW, Burr GS, Hughen KA, Kromer B, McCormac G, van der Plicht J, Spurk M. 1998. IntCa198 radiocarbon age calibration, 24,000-0 cal BP. Radiocarbon 40(3):1041-83.

van Klinken GJ. 1999. Bone collagen quality indicators for paleodietary and radiocarbon measurements. Journal of Archaeological Science 26:687-95.

Vogel JS, Southon JR, Nelson DE, Brown TA. 1984. Performance of catalytically condensed carbon for use in accelerator mass spectrometry. Nuclear Instruments and Methods in Physics Research B 5:289. 